1 Secretaria Municipal de Saúde do Recife, Unidade de Acolhimento para Usuários Dependentes de Álcool, Crack e Outras Drogas - Recife (PE), Brasil. Fundação Oswaldo Cruz (Fiocruz), Centro de Pesquisas Aggeu Magalhães (CPqAM), Laboratório de Análise dos Sistemas de Informação em Saúde (Labsis) - Recife (PE), Brasil.

gracasborges@gmail.com

2 Fundação Oswaldo Cruz (Fiocruz), Centro de Pesquisas Aggeu Magalhães (CPqAM) - Recife (PE), Brasil. Universidade de Pernambuco (UPE), Faculdade de Medicina Recife (PE), Brasil. terezalyra@cpqam.fiocruz

\section{O beber feminino: socialização e solidão}

\author{
The female drinking: socialization and loneliness
}

Maria das Graças Borges da Silva', Tereza Maciel Lyra²

RESUMO Este estudo se propõe a conhecer o significado do beber entre mulheres que sofrem de alcoolismo e buscam tratamento através de um serviço especializado. Apresenta natureza qualitativa e é ancorado à teoria das representações sociais, utilizando questionário e entrevista em profundidade. As participantes revelam que o início do beber significa socialização e prazer, porém, com a dependência do álcool, ele acende o preconceito e afastamento das pessoas, gerando solidão devido à baixa tolerância social em relação ao hábito de mulheres beberem nocivamente. Elas ainda apontam uma percepção negativa desta dependência, sendo a solidão o significado mais representativo. E se sentem mais penalizadas do que os homens.

PALAVRAS-CHAVE Mulheres; Bebidas alcoólicas; Socialização; Preconceito; Solidão.

ABSTRACT This study aims to know the meaning of drinking among women who suffer from alcoholism and seek treatment through a specialized service. It presents a qualitative nature and it is anchored to the social representations theory, using a questionnaire and in-depth interview. The participants reveal that the onset of drinking means socialization and pleasure, however, with the alcohol dependence, it lights the prejudice and the removal of people, resulting in loneliness due to low social tolerance in relation to the habit of women drinking harmfully. They also point to a negative perception of this dependence, being loneliness the most representative meaning. And they feel more penalized than men.

KEYWORDS Women; Alcoholic beverages; Socialization; Prejudice; Loneliness. 


\section{Introdução}

A Organização Mundial da Saúde (OMS), em 2003, revelou que o número de mulheres com problemas relacionados ao uso abusivo de álcool triplicou nos últimos anos, em nível mundial, destacando a América do Sul e incluindo o Brasil (BAUER, 2004). Postula que este crescimento esteja associado à entrada da mulher no mercado de trabalho e na vida política, ou seja, na vida pública e no processo de poder escolher (PRETTO, 2004).

Estudos recentes revelam que o álcool é a droga mais utilizada pelos brasileiros e pelas brasileiras, em relação aos outros tipos de drogas psicotrópicas (BRASIL, 2010). A cachaça, por exemplo, apesar de ser uma bebida com elevado teor alcoólico (superior a 40\%), constitui-se como uma das mais consumidas pelos brasileiros, pois, além de ser uma bebida genuinamente brasileira, é ainda aquela que tem o custo mais acessível para a população de forma geral, quando comparada com aquelas que apresentam similaridade em relação ao teor alcoólico. Então, isso explica o seu elevado consumo no País (CHALITA, 2010).

Pesquisa realizada em 2006, pela Secretaria Nacional de Políticas sobre Drogas (Senad), em parceria com a Unidade de Pesquisa em Álcool e Drogas (Uniad), da Universidade Federal de São Paulo (Unifesp), verificou, em uma amostra de 1.152 adultos brasileiros que faziam uso do álcool, que $45 \%$ deles tinham problemas decorrentes do beber, no momento da pesquisa ou no passado, sendo $58 \%$ homens e $26 \%$ mulheres (BRASIL, 2007). E que o consumo abusivo de álcool é responsável por $10 \%$ dos problemas de saúde pública no Brasil, sendo a dependência do álcool a terceira maior doença do País (BRASIL, 2010).

Todavia, existem várias suposições para o uso abusivo de bebidas alcoólicas pelas pessoas, partindo da premissa de que tanto as mulheres quanto os homens começam a beber, bebem abusivamente ou permanecem bebendo porque o álcool, de certo modo, promove ou recompensa o seu comportamento, induzindo a sensação de prazer, a remoção do desconforto, o aumento da interação social, além de ajudar a abolir lembranças desagradáveis (WILSNACK; WILSNACK; OBOT, 2005; GRIFFITH, 2005).

De acordo com Nóbrega e Oliveira (2005), as mulheres geralmente fazem uso nocivo de álcool a partir da ocorrência de eventos vitais significativos, como: perda de alguém querido, seja por falecimento ou por separação, diferentemente dos homens, que atribuem este uso a eventos relacionados ao trabalho e aos amigos. Então, como consequência deste uso, homens expõem comumente queixas de ordens legais e ocupacionais. Já as mulheres, por outro lado, têm queixas biológicas e familiares.

Ainda segundo os mesmos autores, em suas pesquisas, a visão que a sociedade tem sobre a dependência do álcool na mulher é preconceituosa. As mulheres são consideradas mais imorais, com comportamentos inadequados; sofrem com a estigmatização e acabam por procurar tratamento com menos frequência do que os homens, o que lhes acarreta mais comprometimentos ao longo do tempo. Assim, a perda do apoio social, pelas mulheres usuárias de álcool, acontece mais rapidamente do que com os homens, devido à baixa tolerância social em relação ao fato de elas beberem abusivamente. Elas são avaliadas como renunciantes dos papéis de esposas, mães e filhas, dentre outros. Também, entre as próprias mulheres que sofrem com o uso abusivo de álcool, a atitude expressada é a aversão. Tais percepções, errôneas com frequência, transparecem nas atitudes de alguns profissionais de saúde, que veem tais mulheres como pessoas com desvios de personalidade, particularmente inacessíveis (SIMÃO; KERR-CORREA; DALBEN, 2002).

Simão, Kerr-Correa e Dalben (2002) ainda acrescentam que existe uma ideia de que o sexo feminino controla melhor a ingestão de bebidas alcoólicas, o que poderia colaborar 
para que o diagnóstico de dependência do álcool fosse feito mais tardiamente nas mulheres do que nos homens. Possivelmente, mesmo diante de consequências físicas, psíquicas e/ou sociais decorrentes desta dependência, os profissionais de saúde não conseguem estabelecer as correlações; em geral, têm muita dificuldade de diagnosticar a dependência de álcool em mulheres. O preconceito da população em geral e das próprias mulheres em relação a essa problemática, bem como a relutância de alguns médicos em lidar com a dependência do álcool para as mulheres, acabam por dificultar o acesso das mesmas aos centros de diagnóstico e tratamento. Têm-se, assim, mulheres envergonhadas, que procuram ajuda indiretamente, com queixas vagas sobre sua saúde física e/ ou psíquica, ocultando seu principal probleMa (NÓBREGA; OLIVEIRA, 2005).

Hochgraf (1995) na sua pesquisa indica que há um maior número de mulheres do que de homens com dependência de álcool, com histórico de tentativa de suicídio. Para a autora, a relação entre dependência de álcool e tentativa de suicídio está ligada não só a transtornos afetivos, como também à erosão das redes sociais, a prejuízos nas relações interpessoais e a distúrbios do controle de impulsos.

Estudos realizados sobre a dependência alcoólica, para ambos os sexos, em uma clínica especializada, identificaram que as mulheres com essa patologia apresentaram baixa autoestima. Indicaram que elas tinham, significativamente, mais depressão, assim como tendências e pensamentos paranoides. Revelaram, ainda, que as comorbidades mais frequentes no gênero feminino são os diagnósticos psiquiátricos de transtornos de ansiedade e transtornos de humor, enquanto os homens com diagnóstico expressivo apresentaram transtornos de personalidade (NOVAES, ET AL., 2000).

Para Griffith (2005), ainda que as mulheres comecem a beber nocivamente mais tarde do que os homens, a forma como metabolizam o álcool parece pô-las em maior risco de desenvolver complicações físicas mais precocemente do que os homens.

Segundo Hochgraf e Brasiliano (2004), as complicações físicas mais frequentes são hemorragia gastrointestinal, cirrose hepática, prejuízo cognitivo, hipertensão e desnutrição. O beber nocivo e crônico é ainda associado à inibição de ovulação, à infertilidade e a diversos problemas ginecológicos e obstétricos. Isso ocorre porque o desenvolvimento da dependência do álcool em mulheres passa por diferentes caminhos daqueles percorridos pelos homens. Biologicamente, elas são menos tolerantes ao álcool do que os homens, e atingem concentrações sanguíneas de álcool mais altas com as mesmas doses, devido à menor quantidade de água corporal, em função de maior quantidade de gordura. Tudo isso associado a uma menor quantidade de enzimas que metabolizam o álcool, o que implica no fato de que as mulheres precisam da metade da dose ingerida pelos homens para se intoxicarem, sempre levando em conta seu peso e altura (MASUR, 2004).

A literatura atual vem avançando em relação a investigar as desigualdades de gênero no que tange ao consumo de álcool, e às particularidades daí destacadas. Mesmo assim, ainda persistem os estereótipos maior agressividade e tendência ao isolamento -, além de falhas no cumprimento do papel familiar são mais comumente associadas às mulheres do que aos homens dependentes de alguma droga psicotrópica. Logo, é provável que atitudes preconceituosas dificultem o aprofundamento das especificidades do consumo nocivo de álcool pelas mulheres (SANCHES ET AL., 2003).

Embora muitas pessoas ainda empreguem os termos sexo e gênero como sinônimos, trata-se de dois conceitos que se referem a aspectos distintos da vida humana. Adotamos que o sexo se estabelece no nascimento, com base nas características da genitália externa, e diz respeito à procriação, à reprodução biológica. E o gênero é um elemento 
constitutivo de relações sociais baseadas nas diferenças percebidas entre os sexos (JARDIM, 2003; CÉSAR, 2006).

Enfim, o cenário atual, com o aumento do consumo de bebidas alcoólicas nocivas e a dependência do álcool entre mulheres, assim como suas prováveis decorrências, constituem um problema significativo, que assinala a importância de investigar as especificidades da dependência do álcool, analisando questões relacionadas à mulher no espaço social.

Participaram do estudo mulheres atendidas em um Centro de Atenção Psicossocial de Álcool e outras Drogas (Capsad), com diagnóstico estabelecido de dependência do álcool, entendendo-o como doença crônica com fatores genéticos, psicossociais e ambientais, que influenciam seu desenvolvimento e suas manifestações.

Deste modo, conhecer como se dá esta realidade por meio do relato das próprias mulheres torna-se importante, no sentido de compreender o comportamento feminino quanto à dependência de álcool.

\section{Procedimentos metodológicos}

Adotou-se uma abordagem qualitativa, através da técnica da análise de conteúdo, que procurou compreender as percepções, representações sociais e o ponto de vista das participantes no seu cotidiano, em relação à dependência do álcool. Segundo Minayo (1999), a pesquisa qualitativa almeja um aprofundamento maior da realidade, caminhando para um universo de significações, motivos, aspirações, atitudes, crenças e valores que permitem alcançar os aspectos particulares expressos nas falas das mulheres entrevistadas, importantes para o alcance dos objetivos deste estudo.

Para isso, foi utilizada, como norteadora, a teoria das representações sociais dentro de sua perspectiva processual, em que é considerada a relação dialética entre o social e o individual para identificar a visão de mundo que as entrevistadas têm e empregam na forma de agir e se posicionar em relação à dependência do álcool (GOLDENBERG; MARSIGLIA; GOMES, 2003).

Os dados deste estudo provêm de uma pesquisa original através de uma amostra que foi intencional, composta por mulheres com diagnóstico estabelecido da dependência do álcool, sem outras dependências químicas, e maiores de idade, no Capsad do Sistema Único de Saúde (SUS) para atendimentos de ambos os sexos em Recife (PE). Vale citar que todas as participantes se encontravam em tratamento na modalidade, com dois encontros de grupos semanais e um atendimento mensal do psiquiátra e do clínico.

A escolha por esse cenário de investigação se deu pela relevância de sua representatividade para o tratamento de transtornos relacionados ao álcool e outras drogas deste município. A coleta de dados foi realizada em três etapas, a saber:

A primeira foi a escolha das entrevistadas, que sucedeu as observações dos prontuários indicados pela equipe interdisciplinar do Capsad. A classificação adotada pelo SUS é a Classificação Internacional de Doenças - $10^{\text {a }}$ edição (CID-10). Outro critério foi o de que as mulheres estivessem em tratamento no serviço há pelo menos seis meses, com diagnóstico exclusivo de dependência do álcool, e fossem maiores de 18 anos, totalizando cinco prontuários.

A segunda etapa foi a caracterização das participantes, através de questionário sociodemográfico, com questões referentes a: idade, religião, escolaridade, situação conjugal atual, situação profissional, moradia e renda familiar. Os dados levantados foram confrontados com a literatura.

Por fim, foram realizadas entrevistas semiestruturadas. Ou seja, foi utilizada a "técnica em que o investigador encontra-se frente ao investigado e lhe formula 
perguntas, com o objetivo de obtenção dos dados que interessam à investigação" (GIL, 1999, P. 117). As entrevistas foram analisadas a partir do método de análise de conteúdo, sendo utilizada a técnica de Condensação de Significados, que consiste em buscar, na fala do entrevistado, a ideia central do seu discurso, de forma condensada, sem perder a sua essência (KVALE, 1999).

As entrevistas tiveram perguntas direcionadas ao cumprimento dos objetivos da pesquisa, com questões norteadoras, que abrangem três aspectos: afetivo, cognitivo e de conduta. No aspecto afetivo, o objetivo foi para identificar o significado, os sentimentos e as percepções em relação à dependência de álcool e o julgamento que as participantes fazem sobre mulheres que bebem. No aspecto cognitivo, tiveram o objetivo de identificar as informações que as participantes apresentavam sobre dependência de álcool, formas de utilização do álcool, justificativas para o consumo e consequência do uso. E no aspecto de conduta o objetivo foi para compreender quais os caminhos utilizados para o enfrentamento dessa problemática. O presente artigo foca na análise do aspecto afetivo.

A pesquisa segue os preceitos da Resolução no 196/96, do Conselho Nacional de Saúde, que rege as pesquisas envolvendo seres humanos. O protocolo deste estudo foi aprovado pelo Comitê de Ética em Pesquisa sob o parecer $n^{\circ} 18 / 2011$. Todas as participantes assinaram o Termo de Consentimento Livre e Esclarecido antes de qualquer etapa da entrevista.

Previamente à entrevista, foi realizado um contato para marcar dia e hora mais convenientes para as participantes. Para garantir a confidencialidade, e, por outro lado, resguardar uma identidade, optou-se por apresentar às entrevistadas nomes de rosas com seus significados. Cada entrevistada escolheu o nome de rosa com o qual seria tratada na apresentação dos resultados. Tal escolha gerou mais um elemento de contribuição para análise das entrevistas, pois os nomes escolhidos guardaram associações com os diferentes perfis das entrevistadas.

Todas as mulheres em tratamento entre junho e agosto de 2011 foram entrevistadas, totalizando cinco mulheres. A proposta de trabalho foi submetida à avaliação da equipe interdisciplinar da unidade de saúde, composta por psicóloga, enfermeira, assistente social, terapeuta ocupacional, médico clínico e médico psiquiatra, entre outros profissionais. Todos consideraram que as usuárias estavam aptas a serem entrevistadas, resguardados os critérios éticos.

\section{Resultados e discussão}

O primeiro momento refere-se à caracterização das participantes. Nesse sentido, o perfil das mulheres pesquisadas revelou os seguintes dados:

- Rosa Castanha Chá (que significa 'respeito'): 69 anos; solteira; tem filhos e filha; casa própria; ensino fundamental incompleto; católica; mora com a família; renda familiar maior do que um salário mínimo; recebe auxílio da previdência; chegou ao serviço pela ambulância; não houve percepção dos efeitos do álcool em seu organismo e nem em sua vida. Iniciou o uso da bebida aos 15 anos.

- Rosa Amarela (cujo significado é 'felicidade'): 57 anos; solteira; não tem filhos; casa própria; ensino fundamental incompleto; católica; mora sozinha; renda familiar maior do que um salário mínimo; recebe a aposentadoria de seu pai; não trabalha; chegou motivada pela vizinha e achava que não era doença. Iniciou o uso da bebida aos 16 anos.

- Rosa Vermelha (que simboliza 'paixão'): 52 anos; separada; tem filha; casa própria; ensino fundamental completo; protestante; mora sozinha; renda familiar menor do que um salário mínimo; trabalha sem carteira 
assinada; chegou com ajuda de uma colega, com queixa principal de depressão. Iniciou o uso da bebida aos 18 anos.

- Rosa Roxa (que representa o 'amor materno'): 59 anos; casada; tem filhos e filhas; casa alugada; ensino fundamental incompleto; católica; não trabalha; mora com o marido; renda familiar maior do que um salário mínimo; chegou motivada pela cunhada, com queixa de uso de álcool sem controle e as consequências desse uso. Iniciou o uso da bebida aos 20 anos.

- Rosa (que representa a 'amizade'): 47 anos; separada; tem filha; casa própria; ensino médio completo; candomblecista; mora sozinha; renda familiar menor do que um salário mínimo; trabalha sem carteira assinada; chegou sozinha. Iniciou o uso da bebida aos 14 anos.

Esses dados mostram que o uso de bebidas alcoólicas encontra-se presente na vida das participantes e que o uso nocivo do álcool tem acometido mulheres de diferentes idades, estados civis, religiões, escolaridades e ocupações. Sendo assim, junto com outros aspectos, tais como predisposição biológica, fatores psicológicos e socioculturais, coopera para acarretar a instalação da problemática, o que é defendido pelos estudos de Wilsnack, Wilsnack, Obot (2005) e Griffith (2005). Assim, a caracterização das entrevistadas cooperou para uma melhor compreensão do presente trabalho.

No segundo momento, foi realizada a análise das entrevistas, quando as mulheres deste estudo destacaram quatro aspectos significativos em suas vidas: a tristeza, o prazer, o preconceito e a solidão diante do uso sem controle e da dependência do álcool. Nos discursos das entrevistadas pôde-se observar que elas apresentaram um senso comum sobre o significado da dependência de álcool em mulheres, ou seja, de que ser mulher e beber sem controle é algo condenável, permeado de preconceito. E isso revelou que, em suas experiências, os seus sentimentos tiveram significados semelhantes perante a problemática da dependência do álcool, tendo isso representado uma forma de pensar coletivamente sobre o mesmo assunto, o que é amparado por pensadores da Teoria das Representações Sociais, como Jodelet (2001) e Goldenberg, Marsiglia, Gomes, (2003). Eles afirmam que as representações sociais estão vinculadas a valores, noções e práticas individuais, orientando as condutas no dia a dia das relações sociais e se manifestando através de estereótipos, sentimentos, atitudes, palavras, frases e expressões das pessoas. Portanto, este é o senso comum, socialmente construído e compartilhado entre as participantes.

Também encontramos, nas falas das participantes, a busca de alívio para a ansiedade, para a redução das tensões ou, ainda, de descobrir que, nos encontros sociais, as pessoas fazem coisas que, em outras circunstâncias, não teriam coragem de fazer. O álcool passa a ser usado como base de bem-estar e de socialização, cada vez mais frequente e mais precocemente, passando a fazer parte da vida dessas mulheres. $\mathrm{O}$ achado foi comum entre todas e pôde ser sintetizado pela fala de Rosa Roxa:

Eu não era doente! Não era mesmo. Pois, no início, bebia cerveja sem problemas, ficava leve e sem timidez para dançar em público. la para as festas, ia para os clubes com a minha família e o meu marido. Já era casada, com 27 anos e já era mãe dos meus 4 filhos. Foi porque comecei a beber a cachaça que era bem barata. Porque a cerveja era muito cara. Aí, bebo a cachaça todos os dias e não parei mais. Agora, todo o mundo fala que é muito feio. Mas não falam nada do meu marido, que bebe o final de semana inteiro.

Alegaram, todas as participantes, que o consumo da cachaça causou a dependência da bebida e a manifestação da patologia.

Em relação aos temas preconceito e solidão, as entrevistadas relataram que a 
condição da dependência de álcool é mais difícil para a mulher do que para o homem. Apontaram certa compreensão sobre as questões de preconceito social ao afirmarem que, para a mulher, é mais complicado admitir essa dependência, pois sua família se distancia; e que são as amigas que, às vezes, tentam ajudá-las a enfrentar o problema.

Ao ser identificada, nas falas, a falta de apoio dos familiares, este dado da pesquisa dialoga com Nóbrega e Oliveira (2005), que afirmaram que os homens recebem mais apoio familiar, enquanto as mulheres recebem mais apoio de amigas para procurar um tratamento para a dependência. $\mathrm{O}$ estímulo de um familiar, como fator de motivação para o tratamento, é apontado como importante, tanto para homens como para mulheres. Prontamente, ao não contarem prioritariamente com os familiares, o sentimento de solidão das mulheres, diante da dependência do álcool, se acentua.

Esse achado também é amparado nos estudos de Hochgraf e Brasiliano (2004), e Ancel e Gaussot (1998), que alegam que, na dependência do álcool, a mulher sofre muito preconceito com o estereótipo de maior agressividade e a tendência à solidão, ao isolamento. As falas transcritas ilustram os achados:

Talvez porque ninguém vai me visitar... Mora bem perto, mas ninguém vai me ver. $E$, às vezes, $a$ gente se sente só demais. É muito ruim, a solidão. Hoje, tenho aqui [Capsad], que ajuda muito, não me sinto sozinha. (Rosa Vermelha).

"É muito difícil a gente sobreviver sozinha, ser rejeitada por todos. Hoje vivo na solidão" (Rosa Amarela).

Os relatos acima revelam a perda do apoio social, que é percebida também nas falas das demais entrevistadas e ocorre de forma rápida, devido à baixa tolerância social em relação às mulheres que bebem sem controle e ficam dependentes. Vale ressaltar que as mulheres sofrem menor pressão social para o início do consumo do álcool e, muitas vezes, são até estimuladas a fazerem uso de bebidas. No entanto, sofrem maior pressão para parar o uso, devido à dependência, além de, sobretudo, serem vítimas de maior estigma social (NÓBREGA; OLIVEIRA, 2005; CÉSAR, 2006).

A crítica social em relação à dependência de álcool em mulheres continua sendo muito penosa. É importante mencionar que o uso de álcool não é um fenômeno periférico ou distante da nossa sociedade, não é algo trazido de fora por inimigos externos, mas é produzido e destilado em nosso meio. E sim, pelas leis de mercado - da oferta e da demanda - apoiadas na legalidade e estimuladas pela própria sociedade (BUCHER, 1996).

Para Farah (2004) e Pretto (2004), homens e mulheres evidenciam intolerância em relação à dependência de álcool em mulheres, e, entre elas, a atitude expressada é de aversão. As que apresentam problema com bebidas alcoólicas são objetos de julgamento por parte da sociedade. São censuradas, por abandonarem suas funções de boas esposas e de boas mães, entre outros. Isto se confirma nas falas da maioria das entrevistadas, a exemplo de Rosa Chá Castanha:

Acho uma vergonha, as mulheres que bebem demais. Isso é para os homens. Quando eu bebia, morava na rua, abandonada; vivia sozinha. Não conseguia fazer nada. Perdi tudo! A familia, o trabalho e a minha casa... Eu sabia que os vizinhos falavam que era muito feio uma mulher bêbada caída na rua. Minha filha me expulsou da minha casa, não queria mais eu lá. Passei muito tempo assim na rua. Agora mais não. Estou morando na casa da minha filha, junto com o meu neto. Porque estou sem beber.

Percebe-se que as entrevistadas têm consciência da visão que a sociedade e elas mesmas têm da dependência do álcool, e que a sociedade faz relação entre o uso de álcool e o gênero. A sociedade é mais complacente quando o assunto é a dependência masculina do álcool, e mais rigorosa quando se trata da dependência feminina. As mulheres foram historicamente constituídas como sensíveis, 
emotivas, delicadas, e como tendo funções ligadas à maternidade e aos cuidados (esfera privada). Já os homens foram historicamente relacionados à ideia de força, virilidade e poder (esfera pública) (PRETTO, 2004).

As participantes apontam os prejuízos nos diversos papeis por elas assumidos na sociedade, tais como: o de mãe, o de esposa e o de profissional. Isto é, o álcool comprometeu suas participações sociais. Algumas das entrevistadas trabalham, têm ou tinham duplas jornadas de trabalho, com atribuições no lar. E o uso nocivo do álcool, aos poucos, levou-as a situações de solidão e isolamento, sobretudo por parte de familiares.

Ser mulher sozinha é triste, mas eu tenho os meus cachorros. Sei que não é gente... mas faz companhia. Meu ex-marido fez de tudo para eu não beber mais. No início, a gente bebia junto nos bares. Ele deixou de beber por mim, mas não adiantou de nada. E depois da separação. A minha filha foi morar com minha mãe. Fiquei pior e sem controle - a cachaça. (Rosa).

A fala de Rosa refere que o início do uso do álcool ocorreu socialmente. Tal achado foi comum a todas as entrevistadas, que identificaram o início do uso da bebida como fonte de prazer, lazer e divertimento. Porém, tais fatores foram também percebidos como geradores do uso nocivo e, consequentemente, da instalação e do desenvolvimento da dependência do álcool em suas vidas.

Pode-se observar o fato de que, se o início do uso ocorreu socialmente, através de bebidas com menor teor alcoólico, em seguida, surgiram dificuldades para controlar o consumo de bebidas alcoólicas, assim como surgiu a necessidade de quantidades progressivamente maiores de álcool, para adquirir os efeitos desejados. Nestes casos, o beber social, mediador das relações sociais, se mistura e se confunde com o beber nocivo, apontado no uso da cachaça.

Os principais achados relacionados ao significado da dependência do álcool entre mulheres no presente estudo foram:

- A instalação da dependência do álcool aconteceu como um processo evolutivo, passando pelo uso nocivo da bebida. Nota-se que as participantes abandonaram o uso da cerveja (de menor teor alcoólico) para beber a cachaça (de maior teor), o que demonstrou a necessidade de bebidas mais fortes no seu dia a dia para alcançar efeitos originalmente produzidos por bebidas mais fracas.

- O forte desejo, das participantes, de consumir a cachaça, e a dificuldade de controlar o uso da mesma em termos de início, término e níveis de consumo.

- A percepção da dependência do álcool foi marcada pelo próprio preconceito de gênero, ou seja, a dependência do álcool ainda é uma conduta prevista para o homem e não para a mulher.

- Todas as participantes experimentaram socialmente o consumo de bebidas alcoólicas, em festas e eventos realizados em espaços como clubes, bares etc.

- Elas se sentiram fortalecidas, e com redução da angústia, da tristeza e da solidão durante o tratamento no Capsad, mediante o atendimento focado no grupo e para ambos os sexos, tendo entendido que todos apresentavam a mesma problemática. As participantes informaram que se sentiam bem no grupo porque cada um apoiava o outro e respeitava suas particularidades.

\section{Considerações finais}

Nesta pesquisa pode-se considerar que o significado da dependência do álcool para as participantes foi sintetizado na fala de Rosa: "É, ser mulher e beber é ter um pouco de prazer, diversão, e também é ter uma doença feia, triste, solidão, um vício". 
Como as participantes optaram por escolher o seu nome fantasia, para garantirem a confidencialidade e, ao mesmo tempo, uma identidade, um aspecto não previsto inicialmente pela pesquisa se destacou: a escolha por nomes de rosas gerou momentos tocantes, em relação ao simbolismo e à associação com o estado emocional das participantes no momento da pesquisa. As mulheres entrevistadas possuem uma percepção negativa da dependência de álcool, sendo o preconceito e a solidão os dados mais representativos para elas.

Além disso, as entrevistadas se sentem mais penalizadas do que os homens. Elas se mostraram desabonadas ao procurarem ajuda, justamente pela visão que a sociedade demonstra - compartilhada por todas as participantes -, ao taxá-las de pervertidas, donas de comportamento impróprio e renunciadoras aos papéis tradicionalmente atribuídos a elas, como o de mãe e o de esposa. Esses fatos adiaram a procura delas por tratamento, e isso acabou por trazer-lhes sérios prejuízos.

Faz-se necessário repensar o lugar que o álcool ocupa na configuração e nas relações sociais e familiares das mulheres: a responsabilidade pelo processo saúde-doença é permanente via de mão dupla, visto que o individual se constrói no coletivo, e a qualidade das relações aí estabelecidas influencia na forma como as pessoas irão responder/reagir.

\section{Referências}

ANCEL, P.; GAUSSOT, L. Alcool et alcoolisme: pratiques et représentations. Paris: L’Harmattan, 1998.

BAUER, J. O Alcoolismo e as mulheres: Contexto e Psicologia. São Paulo: Cultrix, 2004.

BRASIL. Secretaria de Atenção à Saúde. Relatório de Gestão 2003-2006: saúde mental no SUS: acesso ao
Finalmente, o estudo evidenciou a importância do atendimento no Centro de Atenção Psicossocial de Álcool e Outras Drogas, do SUS, para ambos os sexos, ao acolher mulheres com dependência de álcool que precisem lidar com sentimentos de tristeza e solidão, além de vivenciar preconceitos e discriminações.

A inclusão social dessas mulheres fez a diferença no sentido de colocá-las no mesmo espaço de cuidado que os homens, quebrando tabus e preconceitos. Assim, garantiu o direitos à cidadania para todos, independentemente de gênero, promovendo a solução dessa problemática vivida entre as mulheres e os homens na saúde, no trabalho, na família e no social.

O trabalho de acolhimento de mulheres com este tipo de sofrimento é essencial para minimizar as consequências dos prejuízos e danos provocados pela dependência do álcool, pois oferece condições para novos conhecimentos, descobertas e para o enfrentamento da realidade, o que contribui para a construção de novos significados e a reestruturação da vida dessas pessoas.

Esperamos que este estudo contribua para a reflexão e a compreensão da necessidade de reconhecer a representação social do beber feminino, e estimule a realização de novas investigações com a finalidade de ampliar o conhecimento desta problemática na perspectiva de gênero, incluindo fatores intrafamiliares, intraindividuais e socioculturais, de forma sistêmica. tratamento e mudança do modelo de atenção. Brasília, DF: Ministério da Saúde, 2007.

. Presidência da República. Secretaria Nacional
de Políticas sobre Drogas. I Levantamento Nacional
sobre o Uso de Álcool, Tabaco e Outras Drogas entre
Universitários das 27 Capitais Brasileiras. Brasília,
DF: SENAD, 2010. Disponível em: $<$ http://www.obid. 
senad.gov.br/portais/OBID/biblioteca/documentos/ Relatorios/328379.pdf>. Acesso em: 20 maio 2014.

BUCHER, R. A Função da Droga no (Dis)

Funcionamento Social. In:__ Drogas e Sociedade

nos Tempos da AIDS. Brasília, DF: UnB, 1996. p. 45-62.

CÉSAR B. A. L. O beber feminino: a marca social do gênero feminino no alcoolismo em mulheres. Cadernos de Saúde Coletiva, Rio de janeiro, v. 14, n. 4, p. 583-4, 2006.

CHALITA, M. A. N.; SILVA, C. R. L. Cachaça: desempenho comercial e qualidade de uma bebida genuinamente brasileira. Instituto de Economia Agrícola - IEA. 2010. (Textos para Discussão, n. 21).

FARAH, M. F. S. Gênero e políticas públicas. Estudos Feministas, Florianópolis, v. 12, n. 1, p. 47-71, 2004.

GOLDENBERG, P.; MARSIGLIA, R. M. G.; GOMES, M. H. A. (Org.). O clássico e novo. Rio de Janeiro: Fiocruz, 2003. p. 197-208.

GIL, A. C. Método e Técnica de Pesquisa Social. São Paulo: Atlas, 1999. p. 117

GRIFFITH, E. O Tratamento do alcoolismo: um guia para profissionais da saúde. Porto Alegre: Artmed, 2005.

HOCHGRAF, P. B. Alcoolismo feminino: comparação de características sócio-demográficas e padrão de evolução entre homens e mulheres alcoolistas. 1995. Tese (Doutorado em Psiquiatria) - Universidade de São Paulo, São Paulo, 1995.

HOCHGRAF, P. B.; BRASILIANO, S. Mulheres farmacodependentes: uma experiência brasileira [internet]. São Paulo, 2004. Disponível em: <http://apps.einstein. br/alcooledrogas/novosite/atualizacoes/ac_128.htm>. Acesso em: 20 jan. 2010.

KVALE, S. Interviews: An introduction to qualitative research interviewing. Thousand Oaks: Sage. 1999.

JARDIM, S. R. M. Gênero e educação: abordagens e concepções em dissertações de mestrado no Estado de São Paulo. 2003. (Pós-graduação em Educação)
- Universidade Federal de São Carlos, São Carlos, 2003. Disponível em: <http://www.scielo.br >. Acesso em: 20 maio 2010.

JODELET, D. As representações sociais. Rio de Janeiro: UERJ, 2001.

MASUR, J. O que é alcoolismo. São Paulo: Brasiliense, 2004.

MINAYO, M. C. S. O desafio do conhecimento: pesquisa qualitativa em saúde. 6. ed. São Paulo: Hucitec; Rio de Janeiro: Abrasco, 1999.

NÓBREGA, M. P. S.; OLIVEIRA, E. M. Mulheres usuárias de álcool: análise qualitativa. Revista de Saúde Pública, São Paulo, v. 39, n. 5, p. 816-823, 2005.

NOVAES, C. et al., Impacto do alcoolismo em mulheres: repercussões clínicas. Revista de Psiquiatria Clínica, v. 27, n. 1, p. 16-21, jan./fev. 2000.

PRETTO, Z. O atravessamento da história do gênero nas relações atuais de gênero. Florianópolis: UFSC, 2004.

SANCHES, A. F. et al., Gender, Culture and problems associated with alcohol: preliminary analysis of the Brazilian part of multinational Study. In: 29th Annual Alcohol Epidemiology Symposium of the Kettil Bruun Society, 2003, Kraków. Global Marketplace for Social Alcohol Research, 2003.

SIMÃO, M.; KERR-CORREA, F.; DALBE, I. Mulheres e homens alcoolistas: um estudo comparativo de fatores sociais, familiares e de evolução. Revista Brasileira de Psiquiatria, São Paulo, v. 24, n. 3, p. 121-129, set. 2002.

\section{WILSNACK R. W.; WILSNACK S. C.; OBOT, I. S. Why} study gender, alcohol and culture? In: WORLD HEALTH ORGANIZATION. Alcohol, gender and drinking problems: perspectives from and middle income countries. Geneva: Department of Mental Health and Substance Abuse, 2005.

Recebido para publicação em abril de 2014 Versão final em dezembro de 2014

Conflito de interesse: inexistente

Suporte financeiro: não houve 